\title{
Discourse on the Method of Rightly Conducting one's Reason and Seeking Truth in the Sciences
}

\author{
René Descartes
}

Copyright ( Jonathan Bennett 2017. All rights reserved

[Brackets] enclose editorial explanations. Small ·dots enclose material that has been added, but can be read as though it were part of the original text. Occasional •bullets, and also indenting of passages that are not quotations, are meant as aids to grasping the structure of a sentence or a thought. Every four-point ellipsis .... indicates the omission of a brief passage that seems to present more difficulty than it is worth. Given this work's full title, you can see that it is wrong to call it, for short, 'Discourse on Method' with no 'the'.

First launched: June 2005

\section{Contents}

Part 1

Part 2

Part 3

Part 4

Part 5

Part 6
1

5

11

14

18

24 
If this discourse seems too long to be read at a sitting you may divide it into six parts. In $\mathbf{1}$ you will find various considerations regarding the sciences; in $\mathbf{2}$ the main rules of the method that the author has sought; in $\mathbf{3}$ some of the moral rules he has derived from this method; in 4 the arguments by which he proves the existence of God and the human soul, on which his metaphysics is based; in $\mathbf{5}$ the order of the questions in physics that he has investigated, particularly the explanation of the movement of the heart and of some other problems in the medical sphere, and also the difference between our soul and that of the lower animals; and in $\mathbf{6}$ the things he believes are needed if we are to go further than he has in the investigation of nature, and his reasons for writing this discourse.

\section{Part 1}

-Good sense is the best shared-out thing in the world; for everyone thinks he has such a good supply of it that he doesn't want more, even if he is extremely hard to please about other things. Since it's not likely that everyone is mistaken about this, it is evidence that

the $\bullet$ power of judging well and of telling the true from the false-which is what we properly call ' $\operatorname{good}$ sense' or •reason'-is naturally equal in all men;

thus it is also evidence that

our opinions differ not because some of us are more reasonable than others, but solely because we take our thoughts along different paths and don't attend to the same things.

For it isn't enough to have a good mind; what matters most is using it well. 'Sheer quality of intellect doesn't make the difference between good and bad : the greatest souls are capable of the greatest vices as well as the greatest virtues. -Nor is nimbleness of intellect the key to making discoveries : those who go very slowly but always on the right path can make much greater progress than those who sprint and go astray.
As for me, I have never presumed my mind to be in any way better than the minds of people in general. Indeed, I have often 'had a sense of being less well endowed than others: I have wished to be as •quick-witted as some others, or to match their -sharpness and clarity of imagination, or to have a $\bullet$ memory that is as capacious (or as promptly serviceable) as theirs is. And these three are the only qualities I know of that serve to perfect the mind, making one mind more perfect than another·. As for $\bullet$ reason or $\bullet$ good $\cdot$ sense, I'm inclined to believe that it exists whole and complete in each of us, because it is the only thing that makes us men and distinguishes us from the lower animals. In this I am following the common opinion of the philosophers, who say that a quality that admits of differences in degree can't be one that marks the difference between one species and another-it can only be an 'accident', a relatively trivial and superficial property, of anything that has it

But I don't hesitate to report my opinion that in one respect I am above the common run of people. Ever since my youth I have been lucky enough to find myself on certain paths that led me to thoughts and maxims from which I developed a method; and this method, it seems to me, 
enables me to increase my knowledge gradually, raising it a little at a time to the highest point allowed by the averageness of my mind and the brevity of my life. There are two reasons, one $\bullet$ personal and the other $\bullet$ general, why I might expect that my method won't amount to much • •In making judgments about myself I always try to lean towards diffidence and away from arrogance; and $\bullet$ when I cast a philosophical eye on the various activities and undertakings of mankind, I regard almost all of them as pointless and useless. And yet, ·despite these two facts·, I have already achieved such results from this method that I'm extremely satisfied with how far I think I have already gone in the search for truth, and am so hopeful about the future that if any purely human occupation has solid worth and importance I venture to think it is the one I have chosen. [Here 'purely human occupation' = 'occupation that doesn't bring in revealed religion'.]

Still, I may be wrong: perhaps what I take to be gold and diamonds is merely copper and glass! I know how prone we are to err in matters that concern us, and also how cautious we should be in accepting the favourable judgments of our friends. But these thoughts won't lead me to be secretive about my method. On the contrary•, I don't mind revealing in this discourse what paths I have followed, laying bare my life as though in a picture, so that everyone can make his own judgment on it, and ${ }^{\bullet}$ when I learn what people think of it I'll be able to add that as a new source of instruction to the ones I'm accustomed to using.

So I don't aim here to teach the method that everyone must follow if he is to direct $\bullet$ his reason correctly, but only to display how I have tried to direct $\bullet$ my own. People who go in for laying down rules for others must think they are more skillful than the others; and they are at fault if they make the slightest mistake. But I'm not one of those, and am not exposed to blame as they are. I am presenting this work only as a history — or if you prefer, a fable-in which you may find certain examples that are worth imitating; and if along with those you also find various others that you would be right not to follow, -that doesn't mean that I'm at fault. So I hope that what I'm offering will be useful for some without being harmful to anyone, and that everyone will give me credit for my openness.

From my childhood they fed me books, and because people convinced me that these could give me clear and certain knowledge of everything useful in life, I was extremely eager to learn them. But no sooner had I completed the whole course of study that normally takes one straight into the ranks of the 'learned' than I completely changed my mind -about what this education could do for me. For I found myself tangled in so many doubts and errors that I came to think that my attempts to become educated had done me no good except to give me a steadily widening view of my ignorance! ·Could I infer anything quite general from this failure on myself in particular? I couldn't legitimately do so if $\bullet$ the college I attended was no good, or if $\bullet$ I was slack in my studies, or if $\bullet$ I wasn't intelligent enough, or if $\bullet$ I happened to be living at a time when the life of the intellect was generally at a low ebb. But none of these seemed to me to be so·

-I was in one of the most famous colleges in Europe: 'If there are learned men anywhere in the world,' I thought, 'there must be some here.' •I had learned there everything that the others were learning; indeed, not being satisfied with the sciences [here = 'theoretically organised topics of study'] that they taught us, I had whipped through every book I could get my hands on concerning the sciences that are considered most abstruse and extraordinary. Along with that, $\bullet$ I knew how others judged me, and I didn't see them regarding me as -intellectually inferior to my fellow students, 
even though some at least of the students were regarded by their teachers as very able : several of them had already been picked as future replacements for our teachers. And finally, •the present age seemed to me to be as flourishing, and as rich in good minds, as any before it.

This -quartet of facts - encouraged me to take my own situation as a basis for judging how things stood for other people -and other times., and to think there was no knowledge in the world such as I had previously been led to hope for.

But I never lost my respect for the curriculum of the college. I knew that $\bullet$ the languages learned there are necessary if one wants to grasp the works of the ancients; that the charm of -fables awakens the mind; that the memorable deeds encountered in •histories uplift the mind and-if read with discretion-help to shape one's judgment; that reading -good books is like having a conversation with the most distinguished men of past ages, namely their authors-indeed, a carefully prepared conversation in which they reveal to us only the best of their thoughts; that -oratory has incomparable powers and beauties; that poetry has quite ravishing delicacy and sweetness; that $\bullet$ mathematics contains some very subtle devices that serve not only to satisfy those who are intrigued by mathematical problems but also to help with all practical and mechanical endeavours and to lessen men's labours; that writings on •morals contain many very useful teachings and exhortations to virtue; that $\bullet$ theology teaches us the way to heaven; that -philosophy gives us the means of speaking plausibly about any subject and of being admired by the less learned; that $\bullet$ law, medicine, and other sciences bring honours and riches to those who study them; and, finally, that it is good to have studied •all these subjects-even those full of superstition and falsehood-in order to know their true value and guard against being deceived by them.

But I thought I had already spent long enough on languages and on reading the works of the ancients, both their -histories and their $\bullet$ fables. For conversing with people of past centuries is rather like travelling. -The latter is all right in its way : it is good to know something of various peoples' ways of life, so that we may judge our own more soundly and not think-as those who have seen nothing of the world often do-that every departure from our way of life is ridiculous and irrational. But if you spend too much time travelling you will end up being a stranger in your own country; and someone who is too absorbed in studying the practices of past ages usually remains quite ignorant about those of the present century. And such studies, whether or not carried to excess, have their own inherent dangers. - Fables make us imagine many events as possible when they are not. And even the most accurate $\bullet$ histories, if they don't alter or exaggerate things' importance so as to provide a better 'read', are likely to falsify things in a different way: such histories omit most of the meaner and the less striking factors in a situation, so that what they do include appears in a false light, ·looking grander than it really was. And a result of that is that those who regulate their conduct by examples drawn from these works are liable to fall into the excesses of the knights-errant in our tales of chivalry, and make plans that they haven't the power to carry out.

I valued oratory and loved poetry; but I thought that each of these was a mental gift rather than something to be achieved through study. People with the strongest reasoning and the most skill at ordering their thoughts so as to make them clear and intelligible are always the most persuasive, even if they speak only a provincial dialect and have never learned rhetoric. And those who have the most pleasing fancies and know how to express them with the 
most embellishment and sweetness would be the best poets even if they knew nothing of poetry as a discipline.

I especially enjoyed mathematics, because of the certainty and evidentness of its reasonings. But I hadn't yet seen what its real use is: I thought it was of service only in the mechanical arts, and was surprised that on such firm and solid foundations nothing had been built that was more exalted than the likes of engineering, road-building, and so on $\cdot$ I contrasted this situation $(\cdot$ minor structures on a magnificently firm foundation.) with the moral writings of the ancient pagans, which I likened to very proud and magnificent palaces built only on sand and mud (·wonderful structures on shaky foundations·). They praise the virtues, making them appear more admirable than anything else in the world; but they don't adequately explain how to tell when something is a virtue, and often what they call by this fine name 'virtue' is merely an instance of callousness, or vanity, or despair-or parricide!

I revered our theology, and thought I had as much right to reach heaven as anyone. But having learned as a certain fact that the way to heaven is as open to the most ignorant as to the most learned, and that the revealed truths that guide us there are above our intellect, I wouldn't have ventured to submit them to my weak reasonings. To examine them and succeed in this, I thought, I would need to get special help from heaven and to be more than a mere man.

All I want to say about philosophy are these two things. -Philosophy has been pursued for many centuries by the best minds, and yet everything in it is still disputed and hence doubtful; and I wasn't so arrogant as to hope to achieve more in philosophy than others had done. ${ }^{\circ}$ Considering how many different opinions learned men may maintain on a single question - where at most one can be true-I regarded everything that was merely probable as being near enough to false. -In short, taking the two points in reverse order: I had no confidence in •any of philosophy's 'results' or •in my ability to improve that situation.

As for the other sciences, in so far as they take their principles from philosophy I thought that nothing solid could have been built on such shaky foundations; and I wasn't induced to learn them by the honour or the riches they offered. For I had no feeling, thank God, that my circumstances obliged me to make science my profession so as to ease my financial condition; and although I didn't make a parade of scorning glory, like a Cynic, I wasn't going to count on glory that I couldn't hope to get except through false pretences. Finally, as for the false sciences, - I saw no need to learn more about them in intellectual self-defence: I thought I already knew their worth well enough not to be open to deception by the promises of an alchemist or the predictions of an astrologer, the tricks of a magician, or the frauds and boasts of those who profess to know more than they do.

That is why, as soon as I was old enough to emerge from the control of my teachers, I entirely abandoned scholarship. Resolving to seek no knowledge except what I could find in myself or read in the great book of the world, I spent the rest of my youth •travelling, •visiting courts and armies, •mixing with people of different temperaments and ranks, - gathering various experiences, •testing myself in the situations that luck put me into, and always •reflecting on whatever came my way so as to profit from it. For it seemed to me that I could find much more truth in the reasonings that people make about matters that concern their interests than in $\bullet a$ scholar's closeted reasonings about theoretical matters. In the $\bullet$ former case, if a person judges wrongly he will soon be punished for this by the upshot; whereas in the latter case there are no practical consequences, and there is nothing 
at stake for the scholar except perhaps that the further his conclusions are from common sense the prouder he will be of them because he will have had to use so much more skill and ingenuity in trying to make them plausible! All through this I had an intense desire to learn to distinguish the true from the false, in order to understand my own actions and to proceed with confidence in this life.

It is true that so long as I merely considered the ways of life of other men I found little basis for confidence, observing in them almost as much variation as I had found previously in the opinions of philosophers. The greatest benefit I extracted from these observations was their showing me many things which, although seeming wild and ridiculous to us, are nevertheless commonly accepted and approved in other great nations; which taught me not to believe too firmly anything I had been convinced of only by example and custom. This would gradually free me from many errors that may obscure our natural light and make us less capable of heeding reason. But after I had spent some years pursuing these studies •in the book of the world, and trying to gain some experience, I made a decision one day to undertake studies •within myself too and to use all the powers of my mind in choosing the paths I should follow. This has worked better for me, I think, than if I had never left my country or my books.

\section{Part 2}

I was in Germany at the time, having been called by the wars that are still going on there. I was returning to the army from the Emperor's coronation when the onset of winter held me in one place $\cdot$ until the weather should clear. Finding no conversation to help me pass the time, and fortunately having no cares or passions to trouble me, I stayed all day shut up alone in a heated room where I was completely free to talk with myself about my own thoughts. One of the first thoughts to come to me was this: there is usually less perfection in 'works composed of several parts and produced by various different craftsmen than there is in -the works of one man. Thus we see that a building started and completed by a single architect will usually be finer and better organized than one that several people have tried to patch up by adapting old walls that had been built for other purposes. Again, these old cities of Europe that have gradually grown from mere villages into large towns are usually less well laid out than the orderly towns that planners lay out as they wish on level ground; so much less that from the way the buildings are arranged in the old cities - a tall one here, a small one there-and - the way they make the streets crooked and irregular, you would think they had been placed where they are by chance rather than by the will of thinking men. (This isn't to deny that if you look at the buildings in the old cities individually you will often find that at least as much skill has gone into the making of 
them as into those of the planned towns.) And when you consider that this is how things stand in old cities although. there have always been officials whose job is to oversee private buildings so as to ensure that they add beauty to public places, you'll grasp that it's hard to achieve something perfect by working only on what others have produced. So it seemed to me that peoples who have grown gradually from a half-savage to a civilized state, and have made their laws only when pushed to do so by the troubles that crimes and quarrels have caused, won't have as good a civil order as do those who from the beginning of their society have observed the basic laws laid down by some wise law-giver. Similarly, the true religion, whose rules are purely God's work, must certainly be ever so much better ordered than any other religion. And in the human sphere: I believe that if Sparta was at one time very flourishing, this wasn't because each of its laws was good (seeing that many were very strange and even contrary to good morals), but because they were devised by a single man and hence were all conducive to the same end. And so I thought that since the sciences contained in books-at least those based on merely probable reasoning and not on demonstrations [= 'strictly, logically, rigorously valid arguments'] - are put together and enlarged piecemeal from the opinions of many different people, they never get as close to the truth as do the simple reasonings that one man of good sense can naturally make concerning anything that comes up. This led me to the thought that because

we were all children before being men, and for years had to be governed by our $\bullet$ desires and our •teachers, which were often in conflict and neither of which always gave us the best advice,

it is almost impossible that our judgments should be as unclouded and as well grounded as they would have been if from the moment of our birth we had had the full use of our reason and had always been guided by it alone.

Admittedly, we never see people pulling down all the houses of a city just so as to rebuild them in a different style to make the streets more attractive; but we do see many individuals having their houses pulled down so as to rebuild them, some even being forced to do so when the houses are in danger of falling down and their foundations are weak. This example convinced me that

it would be truly unreasonable for an individual to -plan to reform a state by changing it from the foundations up, overturning it in order to rebuild it; or to plan to reform the content of the sciences or the established ways of teaching them in the schools;

but I thought nevertheless that something radical could be done at the level of personal intellectual hygiene, namely :

Regarding the opinions which I had previously held, I couldn't do better than set out to get rid of them all at one go, so as then to replace them afterwards with better opinions or even with the same ones after I had straightened them out using reason's plumb-line.

I firmly believed that this would let me conduct my life much better than if I were to build only on old foundations and rely only on principles that I had accepted in my youth without ever examining whether they were true. Even if I were to see various difficulties in this project, they weren't insurmountable, and weren't comparable with the difficulties involved in reforming even minor matters affecting public institutions. These large bodies are too difficult to reconstruct once they are overthrown-indeed, too difficult to prop up once they have been shaken-and when they fall there is bound to be a crash. Furthermore, if they have imperfections-and their very diversity ensures that many of them do-these have doubtless been much smoothed over by custom; and custom has even prevented or imperceptibly corrected many 
imperfections that couldn't be dealt with so well by conscious planning. And a last point: it is almost always easier to put up with their imperfections than to put up with changes in them, just as it is much better to follow •the main roads that wind through mountains, which have gradually become smooth and convenient through frequent use, than to try to follow a $\bullet$ straighter route that has one clambering over rocks and descending into canyons.

That is why I can't in any way approve of those meddlesome and restless characters who, without being called by birth or by fortune to the management of $\bullet$ public affairs, are yet forever thinking up some new reform. If I thought this present work contained the slightest ground for suspecting me of such folly, I would shrink from allowing it to be published. My plan has never gone beyond trying to reform -my own thoughts and to build on a foundation that is all -my own. If I'm pleased enough with my work to present you with this sketch of it, it's not because I would advise anyone to imitate it. Those on whom God has bestowed more of his favours than he has on me - will perhaps have higher aims; but I'm afraid that this project of mine may be too bold for many people. The mere decision to rid myself all the opinions I have hitherto accepted isn't an example that everyone ought to follow! The world is mostly made up of two types of minds for whom it is quite unsuitable. (1) There are those who, believing themselves cleverer than they are, can't help •rushing to judgment and can't •muster the patience to direct all their thoughts in an orderly manner. So that if they once took the liberty of doubting the principles they have accepted and leaving the common path, they would never be able to stay on the straighter path that they ought to take, and would remain lost all their lives. (2) And there are those who are reasonable enough, or modest enough, to think that they can't distinguish true from false as well as some other people by whom they can be taught. These should be content to follow the opinions of those others rather than to seek better opinions themselves.

As for myself, I would undoubtedly have been among the (2) modest followers if I had had only one teacher, or if I had never known how learned people have always differed from one another in their opinions. As things were, I was saved from being a follower by my having no idea of whom to follow . Back in my college days I discovered that

-nothing can be imagined that is too strange or incredible to have been said by some philosopher!

And since then my travels have taught me that

-when people have views quite contrary to ours, that doesn't make them barbarians or savages, and that many of them make use of reason at least as much as we do.

I thought, too, that

-someone who has been brought up from infancy among the French or Germans develops into something different from what he would have been if hethe same man, with the same mind-had always lived among the Chinese or among cannibals;

and

-how even in our fashions of dress the very thing that pleased us ten years ago and may please us again ten years hence strikes us now as extravagant and ridiculous.

-These thoughts convinced me that.

-our convictions come much more from custom and example than from any certain knowledge; and •yet when it comes to proving truths that are hard to discover, a majority vote is downright worthless, because one man on his own is much more likely to hit upon such truths than a whole population is. 
So I couldn't choose anyone whose opinions seemed to me preferable to those of all others, and I found myself pretty much forced to become my own guide.

But, like a man walking alone in the dark, I resolved to go so slowly and to keep looking around me so warily that even if I didn't get far I would at least be sure not to fall. And I wouldn't even • start •my project of - completely rejecting opinions that had slipped into my belief system without being introduced there by reason, until I had $\bullet$ first spent long enough planning the work I was undertaking and looking for the true method of getting all the knowledge my mind was capable of having.

In my younger days my philosophical studies had included some $\bullet$ logic, and my mathematical studies some -geometrical analysis and -algebra. These three skills or sciences, it seemed to me, ought to contribute something to my plan. But on further examination I observed with regard to $\bullet$ logic that syllogisms and most of its other techniques are of less use for learning things than for explaining to others the things they already know (or even, as in Lully's system, for speaking without judgment about matters about which one knows nothing). Logic does contain many excellent and true precepts, but these are mixed in with so much other harmful or superfluous stuff that it is almost as difficult to separate out the truth from the rest as it is to pull a Diana or a Minerva from a rough block of marble by separating out the wanted goddess-shaped marble from the unwanted remainder . As to the $\cdot$-geometrical $\cdot$ analysis of the ancients and the -algebra of the moderns, they cover only highly abstract matters and seem not to be useful for anything; besides which ancient geometrical analysis is always so closely tied to the study of figures [here = 'shapes'] that it can't exercise the intellect without greatly tiring the imagination; and modern algebra is so confined to certain rules and symbols that what emerges from this is not $\bullet$ a science that develops the mind but rather $\bullet$ a confused and obscure art [here $=$ 'set of techniques'] that entangles it. So I thought I should look for some other method that would have the advantages of these three without their defects. Now, just as a state is much better governed when it has only a few laws that are strictly obeyed than when it has a great many laws that can provide an excuse for vices, so I thought that in place of the large number of rules that make up logic I would find the following four to be sufficient, provided that I made and kept to a strong resolution always to obey them. (1) The first was never to accept anything as true if I didn't have evident knowledge of its truth: that is, carefully to avoid jumping to conclusions and preserving old opinions, and to include in my judgments only what presented itself to my mind so vividly and so clearly that I had no basis for calling it in question.

[That last sentence involves a crucial translation point that should be explained. It concerns the French adjectives clair and distinct

and their Latin cousins clarus and distinctus, and of course their corresponding adverbs. Those two have always been translated by 'clear' and 'distinct',

in that order, but this time-honoured translation is demonstrably wrong. A better translation is 'vivid and clear' (in that order), which is adopted here. The crucial point concerns clair. The word can mean 'clear' in our sense, and when Descartes uses it outside the clair et distinct phrase, it sometimes seems to be in that sense. But in that phrase he uses clair in its other meaning - its more common meaning in French—of 'bright' or 'vivid' or the like, as in lumière claire = 'broad daylight'. If in the phrase clair et distinct Descartes meant clair in its lesser meaning of 'clear', then what is there left for distinct to mean? Descartes's one explanation of the two parts this phrase, in his Principles of Philosophy 1:45-6, completely condemns the usual translation. He writes:

I call a perception claire when it is present and accessible to the attentive mind-just as we say that we see something clairement when it is present to the eye's gaze and stimulates it with a sufficient degree of strength and accessibility. I call a perception 
distincte if, as well as being claire, it is so sharply separated from all other perceptions that every part of it is claire.... The example of pain shows that a perception can be claire without being distincte but not vice versa. When someone feels an intense pain, his perception of it is claire, but it isn't always distincte, because people often get this perception muddled with an obscure judgment they make about something that they think exists in the painful spot. ... and so on.

He can't be saying anything as stupid as that intense pain is always clear! His point is that pain is vivid, up-front, not shady or obscure. And for an idea to be distincte is for every nook and cranny of it to be vivid; which is not a bad way of saying that it is in our sense 'clear'. 'Three times in this version, 'see clearly' will occur as a translation of voir clairement; perhaps on these occasions Descartes has in mind partly the thought of seeing something in a sharply detailed way, but he certain has in mind the thought of seeing something right out in the open, this being the notion that also goes with 'vivid'. 'The time-honoured wrong translation has, among its other mischiefs, tended to mask the great extent to which Descartes thought in terms of openness, removal of obscurity, letting light shine on things.]

(2) The second 'was - to divide each of the difficulties I examined into as many parts as possible and as might be required in order to resolve them better.

(3) The third ·was to direct my thoughts in an orderly manner, by -starting with the simplest and most easily known objects in order to move up gradually to knowledge of the most complex, and by stipulating some order even among objects that have no natural order of precedence.

(4) And the last ·was. to make all my enumerations so complete, and my reviews so comprehensive, that I could be sure that I hadn't overlooked anything.

Those long chains of very simple and easy inferences that geometers customarily use to arrive at their most difficult demonstrations had led me to think that $\cdot$ all the things that human beings can know are inter-deducible in that same way, and that nothing can be too remote to be reached eventually, or too well hidden to be discovered-just as long as we refrain from accepting as true anything that isn't, and always keep to the order required for deducing one thing from another. And I didn't have to look far for the things to start with, for I knew already that it must be with the things that are simplest and most easily known. Bearing in mind also that of all those who have pursued truth in the sciences only the mathematicians have been able to find any demonstrations - that is to say, certain and evident reasonings-I had no doubt that I should start with the very things they studied, though only so as to get my mind used to nourishing itself on truths and not being satisfied with bad reasoning. But in this I wasn't aiming to try to learn all the special sciences-.such as astronomy, music, and optics-— that are commonly called 'mathematical'. For I saw that although they deal with different objects they are alike in considering nothing but the various relations or proportions that hold between these objects, and I thought it would be better to study only these proportions taken generally. When I thought of them as proportions amongst objects of some kind, it would only be so as to make it easier for me to know the proportions themselves; and I wouldn't tie the proportions down to these objects, because I wanted to be able later on to apply them all the better to any others that they might fit. Next I observed that in order to know these proportions I would need sometimes to consider them separately, and sometimes merely to remember or understand many together; and this led me to think that in order the better to consider them separately I should take them to be proportions between lines, because I didn't find anything simpler, or anything I could represent more clearly to my imagination and senses. But in order to remember or understand several together, I needed to designate them by 
the briefest possible symbols. This would enable me to take over all that is best in geometrical analysis and in algebra, using the one to correct all the defects of the other.

Strictly observing the few rules I had chosen, I began to tackle problems in •geometry and •algebra, beginning with the simplest and most general and using each truth I found as a rule for finding further truths. And I venture to say that just by proceeding in this manner I became really good at unravelling all the questions that fall under •these two sciences-so good that in the two or three months I spent on this work not only did I solve many problems that I had previously thought very difficult but also, it seemed to me towards the end, even with problems where I was still in the dark I could work out how and how far it was possible to find a solution. This claim won't appear too arrogant if you consider that since there is only one truth concerning any matter, whoever discovers it knows as much about the matter as can be known (if a child who has been taught arithmetic does an addition sum following the rules, he can be sure of having found everything the human mind could find regarding that particular sum). It comes down to this: the method-.my method-- that tells us to follow the correct order, and to enumerate exactly all the relevant factors, contains everything that gives certainty to the rules of arithmetic.

But what I liked best about this method was that by following it I was sure always to use my reason as well as was in my power (perhaps not perfectly). Moreover, as I employed the method I felt my mind getting more and more into the habit of conceiving things sharply and clearly; and as I didn't restrict the method to any particular subject-matter, I hoped to apply it to the problems of the ${ }^{\circ}$ other sciences as usefully as I had to those of algebra. Not that I would have ventured at the outset to tackle every problem that might arise, for that would in itself have been contrary to the order that the method prescribes. But observing that the principles of these sciences must all be derived from philosophy, in which I hadn't yet discovered anything certain, I thought that the first need was to try to establish some certain principles in philosophy. And since this is the most important thing in the world, and the one that is most endangered by rushing to conclusions and holding on to ungrounded old opinions, I thought I shouldn't try to pull it off until I had •reached a more mature age than twenty-three (my age at the time), and had spent a long time preparing myself for this. The preparation was to involve uprooting from my mind all the wrong opinions I had accepted up till then, amassing a variety of experiences to serve later as the subject-matter of my reasonings, and constantly employing the method I had imposed on myself, in order to become increasingly assured in my use of it. 


\section{Part 3}

If you want to rebuild the house you live in, it isn't enough just to $\bullet$ pull it down, to $\bullet$ arrange for materials and architects (or else train yourself in architecture), and to ${ }^{\circ}$ have carefully drawn up the plans; you must also provide yourself with somewhere else to live comfortably while the work is going on. Similarly, so as not to be indecisive in my actions during the time when reason obliged me to be so in my judgments, and in order to live as well as I could during this time, I formed for myself a provisional moral code consisting of just three or four maxims, which I should like to tell you about.

(1) The first was to obey the laws and customs of my country, holding constantly to the religion in which by God's grace I had been instructed from my childhood, and governing myself in all other matters-i.e. all the ones not settled by the law of the land or my religion.- on the basis of the most moderate and least extreme opinions, the opinions commonly accepted in practice by the most sensible of the people with whom I would have to live. For I had begun at this time to count my own opinions as worthless, because I wanted to examine them all, and didn't see how I could do better than in the meantime to follow those of the most sensible men. And although the Persians or Chinese may have men as sensible as any of ours, I thought $\bullet$ that it would serve me best to be guided by those with whom I was going to live, and-a a second reason for going this way.- - that in order to discover what opinions people really held I had to attend to their actions rather than their words. - There are two reasons for this last point. . With our declining standards of behaviour, few people are willing to say everything that they believe; and anyway many people don't know what they believe, since $\bullet$ believing something and $\bullet$ knowing that you believe it are different acts of thinking, and you could have one without the other. Where many opinions were equally well accepted, I chose only the most moderate, both because these are always the most convenient in practice, and probably the best (excess being usually bad), and also so that

if I made a mistake, it wouldn't take me as far from the right path as if I had chosen one extreme when I ought to have adopted the other.

Coming down to details: I counted as excessive all promises by which we give up some of our freedom. Not that I disapproved of laws that allow people to make vows or contracts that ${ }^{\circ}$ oblige them to persevere in some worthy project (or even, for the security of commerce, in something that is neither good nor bad)-this being a remedy for the inconstancy of weak minds. -But I didn't see myself as bound by any contract to remain faithful to any of my earlier beliefs. I saw nothing in the world that remained always in the same state, and for my part I was determined to make my judgments ever more perfect, rather than worse; so I thought I would be sinning against good sense if I took my previous approval of something as • obliging me to regard it as good later on, when it had perhaps ceased to be good or I no longer regarded it as such.

(2) My second maxim was to be as firm and decisive in my actions as I could, and to follow even the most doubtful opinions, once I had adopted them, as constantly as if they had been quite certain. In this I would be imitating travellers who find themselves lost in a forest: rather than •wandering about in all directions or (even worse) -staying in one place, they should $\bullet$ keep walking as straight as they can in one 
direction, not turning aside for slight reasons, even if their choice of direction was a matter of mere chance in the first place; for even if this doesn't bring them to where they want to go it will at least bring them to somewhere that is probably better for them than the middle of a forest. Similarly, since in everyday life we often have to act without delay, it is a most certain truth that when we can't pick out the truest opinions we should follow the most probable ones. And when no opinions appear more probable than any others, we should nevertheless adopt some; and then we should regard those as being-from a practical point of view-not doubtful but most true and certain, because the reason that made us pick on them is itself true and certain. This maxim could free me from all the regrets and remorse that usually trouble the consciences of those weak and stumbling characters who set out on some supposedly good course of action and then later, in their inconstancy, judge it to be bad.

(3) My third maxim was to try always to master $\bullet$ myself rather than $\bullet$ fortune, and change $\bullet$ my desires rather than changing $\bullet$ how things stand in the world. This involved getting the habit of believing that nothing lies entirely within our power except our thoughts, so that after we have done our best in dealing with matters external to us, whatever we fail to achieve is absolutely impossible so far as we are concerned. This seemed to me to be enough, all by itself, to prevent me from having unsatisfied desires and thus to -make me content. For it is the nature of our will to want only what our intellect presents to it as somehow possible; so if we regard all external goods as equally beyond our power, that will certainly save us from regrets over not having goods that seem to be our birthright but which we are deprived of through no fault of our own, any more than we regret not owning the kingdom of China or of Mexico! 'Making a virtue of necessity'-as the phrase goes-we shan't want to be healthy when ill, or free when imprisoned, any more than we now want to have bodies as hard as diamonds or wings to fly like the birds. But I admit that it takes long practice and repeated meditation to get used to seeing everything in this light. I think this was the secret of those philosophers of old who could escape from being dominated by fortune and, despite suffering and poverty, could rival their gods in happiness. By constantly busying themselves with thoughts about the limits that nature had placed on them, they became thoroughly convinced that nothing was in their power except their own thoughts, which was enough to prevent them from being attracted to other things. They were so absolutely in control of their thoughts that this gave them some reason to think themselves richer, more powerful, freer and happier than any men who-however favoured by nature and fortune they may be-don't have this philosophy and so never get such control over all their desires.

[We now come to Descartes's fourth rule of conduct (he didn't head them with numerals). Why at the start of Part 3 did he say that he had adopted 'three or four' moral rules? The excellent editor Ferdinand Alquié conjectures that this is because Descartes sees the fourth as radically unlike the others: they could be generalised to any reasonable person, whereas the fourth is strictly personal to Descartes himself.]

(4) Finally, to conclude this moral code, I decided to review the various occupations of human life, so as to try to choose the best. Without wanting to say anything about other people's occupations, I thought it would be best for me to continue with the very one I was then engaged in, and devote my whole life to cultivating my reason and advancing as far as I could in the knowledge of the truth, following my self-imposed method. Since beginning to use this method I had felt such extreme satisfactions that I didn't think one could enjoy any sweeter or purer ones in this life [= "before we get to heaven']. Every day my method led me to discover truths 
that seemed to me to be quite important and not widely known; my pleasure in this so filled my mind that nothing else mattered to me. The sole basis for maxims (1)-(3) was my plan to continue my self-instruction, -i.e. the course of action decided on in (4) . For God has given each of us a light to distinguish truth from falsehood, and I wouldn't have (1) thought myself obliged to rest content for a single moment with the opinions of others if I hadn't intended in due course to bring my own judgment to bear on them; I couldn't have (2) avoided having scruples about following these opinions, if I hadn't hoped to take every opportunity to discover better ones if there were any; and I couldn't have (3) limited my desires, or been happy, if I hadn't been following a path that I thought was sure to lead me to

all the knowledge of which I was capable,

and in this way to lead me to

all the true goods that were within my power.

For our will tends to pursue (or avoid) only what our intellect represents as good (or bad), so all we need in order to act well is to judge well; and judging as well as we can is all we need to -act as well as we can-that is to say, •to acquire all the virtues and in general all the other attainable goods. With this certainty, one cannot fail to be happy.

Having assured myself of these maxims and set them on one side--out of harm's way, so to speak.-along with the truths of faith, which have always been foremost among my beliefs, I judged that I could freely go about ridding myself of all my other opinions. As I hoped to be able to carry this through better by talking with other men than by staying shut up in the stove-heated room where I had all these thoughts, I resumed my travels before the winter was over. For the next nine years [1619-28] I did nothing but roam from place to place, trying to be a spectator rather than an actor in all the dramas that are played out on the world's stage.
Concentrating on the points in every subject that might make it suspect and lead us into mistakes, I kept uprooting from my mind any errors that might previously have slipped into it. In this I wasn't copying the sceptics, who doubt purely for the sake of doubting and pretend to be always undecided; on the contrary, my whole aim was to reach certainty-to push away the loose earth and sand so as to get to rock or clay. I had pretty fair success in this, I think. ·Here are three features of my procedure that contributed to its success. •When trying to expose the falsity or uncertainty of any proposition, what I brought against it were arguments that were open and certain, not feeble conjectures. II never encountered any proposition so doubtful that I couldn't get from it some fairly certain conclusion, even if it was only the conclusion that it contained nothing certain! •Just as in demolishing an old house we usually keep the materials for use in building a new one, so in destroying all those opinions of mine that I judged to be ill-founded I made various observations and acquired many experiences that I have since used in establishing more certain opinions. Moreover, I continued following my self-imposed method; as well as taking care in general to conduct all my thoughts according to its rules, I occasionally set aside a few hours for · practice, training exercises', applying it to mathematical problems and to certain other problems that I could put into something like mathematical form by separating out from them all the principles of other sciences that I didn't find sufficiently secure. (You will see me perform that kind of separating-out in several of the problems discussed later in this book). Thus, while appearing to live like those who, with no aim except to lead an agreeable and blameless life and to keep their pleasures free from vices, pursue pleasure and fight off boredom by engaging in every honest pastime, I still pursued my project and may have gone further in 
the knowledge of the truth than I would have if I had done nothing but read books or mix with educated men.

Those nine years passed by, however, without my •taking a side on any of the questions that are commonly debated among the learned, or •starting to look for the basis of any philosophy more certain than the commonly accepted one. The example of many fine intellects who had previously had this project, but hadn't met with success (it seemed to me), made me imagine that the task was so hard that I wouldn't have ventured to 'undertake it so soon if I hadn't become aware that some people were spreading the rumour that I had already $\bullet$ completed it. I can't say what basis the rumour had. If my conversation contributed anything to it, that must have been because I admitted my ignorance more openly than is customary for those with a little learning, and perhaps also because I showed the reasons I had for doubting many things that others regard as certain; it won't have been because I boasted of some positive doctrine. But being honest enough not to want to be taken for what I was not, I thought I should try by every means to become worthy of the reputation that was given me by the rumours'. Exactly eight years ago this desire made me resolve to move away from any place where I might have acquaintances and retire to this country [Holland], •where the long duration of the war has led to such a high level of 'civil - discipline that the armies maintained here seem to serve only to make the pleasures of peace all the more secure, and $\bullet$ where, amidst this great mass of busy people who are more concerned with their own affairs than curious about other people's, I have been able to lead a life as solitary and withdrawn as if I were in the most remote desert, while lacking none of the comforts found in the most populous cities.

\section{Part 4}

I don't know whether I should tell you of the first meditations that I had there, for they are perhaps too metaphysical [here = 'abstract'] and uncommon for everyone's taste. But I have to report on them if you are to judge whether the foundations I have chosen are firm enough. I had long been aware that in practical life one sometimes has to act on opinions that one knows to be quite uncertain just as if they were unquestionably $\bullet$ true (I remarked on this above). But now that I wanted to devote myself solely to the search for truth, I thought I needed to do the exact opposite-to reject as if it were absolutely $\bullet$ false everything regarding which I could imagine the least doubt, so as to see whether this left me with anything entirely indubitable to believe. Thus,

-I chose to suppose that nothing was such as our senses led us to imagine,

because our senses sometimes deceive us. Also,

-I rejected as unsound all the arguments I had previously taken as demonstrative [= 'absolutely rigorous'] proofs,

because some men make mistakes in reasoning, even in the simplest questions in geometry, and commit logical fallacies; and I judged that I was as open to this as anyone else. Lastly, 
-I decided to pretend that everything that had ever entered my mind was no more true than the illusions of my dreams,

because all the mental states we are in while awake can also occur while we sleep ·and dream·, without having any truth in them. But no sooner had I embarked on this project than I noticed that while I was trying in this way to think everything to be false it had to be the case that $\bullet$, who was thinking this, was •something. And observing that this truth

\section{I am thinking, therefore I exist}

was so firm and sure that not even the most extravagant suppositions of the sceptics could shake it, I decided that I could accept it without scruple as the first principle of the philosophy I was seeking. [This 'first principle' could be (1) 'I exist' or (2) the connection between 'I am thinking' and 'I exist'-the uncertainty in this version echoes that in Descartes's French.]

Then I looked carefully into what I was. I saw that while I could pretend that I had no body and that there was no world and no place for me to be in, I still couldn't pretend that I didn't exist. I saw on the contrary that from the mere fact that I thought about doubting the truth of other things, it followed quite evidently and certainly that I existed; whereas if I had merely stopped thinking altogether [here = 'stopped being in any conscious mental state'], even if everything else I had ever imagined had been true, I 'would have had no reason to believe that I existed. This taught me that I was a substance whose whole essence or nature is simply to think [here = 'to be in conscious mental states'], and which doesn't need any place, or depend on any material thing, in order to exist. Accordingly this me-this soul that makes me what I am-•is entirely distinct from the body, $\bullet$ is easier to know than the body, and -would still be just what it is even if the body didn't exist.
After that I considered in general what is needed for a proposition to be true and certain: I had just found one that I knew was true and certain, I thought that I ought also to know what this certainty consists in. I observed that the proposition 'I am thinking, therefore I exist' has nothing about it to assure me that I am speaking the truth $\cdot$ when I assert it. except that I see very clearly that in order to think it is necessary to exist. This convinced me that I could take it as a general rule that the things we conceive very vividly and very clearly are all true; but this isn't as powerfully simple a rule as you might think, because there is some difficulty in telling which conceptions are really clear.

Next, I reflected on the fact that I was doubting, and that consequently I wasn't wholly perfect (for I saw clearly that it is a greater perfection to know than to doubt). This led me to the question:

Where did I get my ability to think of something more perfect than I am?

and I drew the obvious conclusion that this ability had to come from-.had to be caused by--something that was in fact more perfect than me. . To explain why I reached that conclusion, I should first explain why I wasn't exercised about such questions as

Where did I get my ability to think of the heavens, the earth, light, heat (and so on)?

It was because I saw nothing in those thoughts that seemed to make them superior to me, $\cdot$ i.e. more perfect than I am·; and that opened the door to a pair of possible explanations for my ability to have them •. (1) If the thoughts in question were true, they could depend on-.i.e. come from--some perfection in my own nature. (2) If they weren't true, I could have derived them from - nothingness - meaning that they could be in me because I had some $\bullet$ defect. But neither of these explanations could hold for the idea of a being more 
perfect than me. For it was obviously impossible (2) to get this from nothingness; and I couldn't have (1) derived it from myself, because the proposition

(1) Something resulted from and depends on something less perfect than it is

is just as contradictory as

(2) Something resulted from nothingness.

So the only possibility left was that the idea had been put into me by -something that truly was more perfect than I was, -something indeed having every perfection of which I could have any idea, that is-to explain myself in one word-by $\bullet$ God. To this I added that since I knew of some perfections that I didn't myself have, I wasn't the only being that existed...., and there had to be some other more perfect being on which I depended and from which I had acquired everything that I had. For if I had existed alone, not depending on anything else, so that my meagre ration of perfections had come from myself, then by that same line of reasoning

-I could have derived from myself all the remaining perfections that I knew I lacked, and thus

-I could myself have been infinite, eternal, unchanging, omniscient, omnipotent; in short,

-I could have had all the perfections that I had been able to discover in God.

[What follows starts with the word Car = 'For'. Descartes seems to be promising a reason for what he has just said, but the promise isn't kept.] For, according to the arguments I have just presented: in order to know as much of God's nature as my nature allows me to know, all I needed was to consider, for each property of which I had some idea, whether having it was a perfection or not; and I was sure that God doesn't have any of the properties that indicate any imperfection, but that he does have all the others. Thus I saw that God could not have doubt, inconstancy, sadness and the like, since I myself would have been very glad to be free from them, -which shows that they are imperfections'. Furthermore, I had ideas of many perceptible bodies (even if I was dreaming, and everything that I saw or imagined was false, I still couldn't deny that the ideas of bodies were in my mind). But since I had already recognized very clearly in my own case that intellectual nature is distinct from bodily nature, and as I observed that

-if a thing is composed of simpler elements - in any way, that shows that it is dependent on something else, and that

-dependence is obviously a defect,

I concluded that

-it couldn't be a perfection in God to be composed of these two natures- the intellectual and the bodily.and consequently that he was not composed of them; and also that if there were any bodies in the world, or any intelligences or other natures that weren't wholly perfect, their being must depend on God's power in such a way that they couldn't stay in existence for a single moment without him.

After that, I wanted to seek other truths: I took up the subject-matter of geometry, which I conceived of as $\bullet$ continuous body, or $\bullet$ a space indefinitely extended in length, breadth and height or depth, and divisible into different parts that can have various shapes and sizes, and can be moved and swapped around in all sorts of way (geometers assume that their subject-matter has all these properties). I went through some of their simpler proofs, and noted that it's because we conceive them as evident [= 'obviously true'] that 
we all regard them as utterly certain. I noted also that these demonstrations gave no assurance-none-of the existence of their subject-matter. For example, I saw that given a triangle its three angles of must equal two right angles; but I saw nothing assuring me that there are any triangles in the world. In contrast with that, when I returned to the scrutiny of the idea I had of a perfect being, I found that

this idea of a perfect being included existence

in the same way as-or even more evidently thanthe idea of a triangle includes the equality of its three angles to two right angles

or

the idea of a sphere includes the equidistance from the centre of all the points on the surface.

Thus I concluded that the existence of this perfect being, God, is at least as certain as any geometrical proof.

Why are many people convinced that there is some difficulty in knowing God, and even in knowing what their soul is? It's because they never raise their minds above things that can be perceived by the senses: they are so used to -thinking of things only in the way that is specially suited to material things, namely by $\bullet$ imagining $\cdot$ or picturing them, that they regard as unintelligible $\cdot$ or $\bullet$ unthinkable anything that they can't $\cdot$ imagine. This shows up in the fact that even the scholastic philosophers take it as a maxim that there is nothing in the intellect that wasn't previously in the senses; -which leads people to find God and the soul problematic, because it is certain that the ideas of God and of the soul have never been 'in the senses'! Trying to •understand these ideas through one's •imagination strikes me as being like trying to $\bullet$ hear sounds or smell odours through •the use of one's eyes. Actually, trying-to-understand-through-imagination is even more absurd than trying-to-hear-or-smell-with-theeyes, because there is this difference: the sense of sight gives us as much assurance of the reality of its objects as do the senses of smell and hearing, whereas our imagination and our senses could never assure us of anything without the aid of our understanding.

Finally, if you are still not really convinced of the existence of God and of your soul by the arguments I have presented, I tell you this: everything else of which you may think you are -more sure-such as your having a body, there being stars and an earth, and the like-is - less certain. For although we have enough certainty for everyday practical purposes about these things, so that it seems wild and irresponsible to call them in question, nevertheless when it is a question of metaphysical certainty we have to admit that there are good reasons for not being entirely sure about them. We need only observe that in sleep we may imagine that we have a different body and see different stars and a different earth, without any of these things being real. This is a reason for having some uncertainty about the existence of our body, the stars, and so on·, because: how do we know that the mental states that come to us in dreams are any more false than the others, seeing that they are often just as lively and sharp? Let the best minds study this question as much as they like, I don't think they'll be able to give any reason that removes this doubt unless they presuppose the existence of God. For, in the first place, what I took just now as a rule, namely that whatever we conceive very vividly and clearly is true, is assured only because ${ }^{\bullet}$ God exists and $\bullet$ is a perfect being, and because everything in us comes from him. It follows that our ideas or notions, being real things that get from God everything that is vivid and clear in them, must be true in every respect in which they are vivid and clear. So if we quite often have ideas containing some falsity, this can only be because there is something confused and shadowy in them; for their confusion etc. is something they share 
with nothingness, which means that they are in us in this confused state only because we aren't completely perfect. And it is evident that it's just as contradictory to suppose that falsity or imperfection as such should come from God as to suppose that truth or perfection should come from nothingness. But if we didn't know that everything real and true within us comes from a perfect and infinite being, then, however vivid and clear our ideas were, we would have no reason to be sure that they had the perfection of being true.

But once the knowledge of God and the soul has made us certain of this rule, it is easy to recognize that the things we imagine in dreams shouldn't make us doubt the truth of the experiences we have when awake. For if someone happened even in sleep to have some very clear idea (if, say, a ddreaming. geometer devised some new proof), his being asleep wouldn't prevent the idea from being true. The commonest error of our dreams consists in their representing various objects to us in the same way as our external senses do; but it doesn't matter-.i.e. it doesn't imply anything specially about dreams.- - that this may lead us to doubt the truth of such ideas, for often they can also mislead us without our being asleep; for example, people with jaundice see everything as yellow, and stars or other very distant bodies appear to us much smaller than they are. For after all, whether we are awake or asleep, we ought never to let ourselves be convinced except by the evidentness of our reason. Note that I say 'our reason', not 'our imagination' or 'our senses'. Even though we 'have a vividly open view of the sun, we mustn't judge on that account that it is only as large as we see it; and we can clearly •imagine a lion's head on a goat's body without having to conclude from this that a chimera exists in the world. For reason doesn't insist that what we thus 'see or -imagine is true. But it does insist that all our ideas or notions must have some foundation of truth; for otherwise it wouldn't be possible that God, who is all-perfect and all-truthful, should have placed them in us. Now, sometimes our imaginings in sleep are at least as lively and detailed as in waking life, but our reasonings when we are asleep are never so evident or complete as when we are awake; so reason also insists that, since our thoughts can't all be true because we aren't perfect, what truth they do possess must inevitably be found in the thoughts we have when awake, rather than in our dreams.

\section{Part 5}

I would like to go on with this, and present the whole chain of other -truths that I deduced from these first ones. But this would involve me in discussing here many questions that are being debated among the learned, and I don't want to get into those quarrels. [This presumably refers to Descartes's views in physics, which contradicted the Aristotelian physics that was still dominant in the universities.] So I think it will be better if I don't follow my inclination and merely say in general what -those other truths are, and leave it to wiser heads to decide whether it would be useful for the public to be told about them in more detail. I have always stuck by my resolve $\bullet$ not to assume any principles except the one I have just used to demonstrate the existence of God and of the soul, and $\bullet$ not to accept anything as true unless it struck me as more open 
and more certain than the demonstrations of the geometers once seemed to be. And yet I venture to say that even under those constraints. it didn't take me long to satisfy myself regarding all the chief difficulties usually discussed in philosophy. And I discovered certain laws that God has established in nature; he has implanted notions of these laws in our minds, in such a way that after adequate reflection we can't doubt that the laws are exactly observed in everything that exists or occurs in the world. Moreover, by considering what follows from these laws I have discovered (it seems to me) many truths that are more useful and important than anything I had previously learned or even hoped to learn.

I tried to explain the most important of these truths in a treatise that certain considerations prevent me from publishing, and I know of no better way to make them known than by summarizing its contents. [Descartes's treatise The World was completed in about 1632-five years before the present work. His reasons for not publishing it are given starting on page 26.] I had planned to include in that work everything I thought I knew about the nature of material things at the time when I was poised to start writing it, but that turned out to be too much to tackle all at once. A painter can't represent all the different sides of a solid body equally well on his flat canvas, and so he chooses one principal side, sets it facing the light, and shades the others so that they are seen only in the course of looking at the favoured side. Well, in just the same way, fearing that I couldn't put into my discourse everything that I wanted to, $\cdot$ I started by (so to speak) letting daylight shine on just • one face of it; specifically·, I undertook merely to expound quite fully what I understood about $\bullet$ light, and then, as the occasions arose, to let the shaded sides of my object (so to speak) enter the picture, one at a time. That is., I planned to add something about •the sun and fixed stars, because almost all light comes from them; about -the heavens, because they transmit light; about •planets, comets and the earth, because they reflect light; about $\bullet$ the bodies on this planet, because they are either coloured or transparent or luminous, and finally about $\bullet$ man, because it is he who sees light. But I wanted to keep these matters still somewhat in the shadows, so as to be free to say what I thought about them without having to follow or to refute the opinions of the learned. My plan for doing this was to leave - our world wholly to the learned folk to argue about, and to speak solely about what would be the case in $\bullet$ a new world that would exist if

God now ${ }^{\bullet}$ created somewhere in imaginary spaces enough matter to compose a world; variously and randomly agitated the different parts of this matter so as to create as confused a chaos as any poets could dream up; and then did nothing but •allow nature to unfold in accordance with the laws he had established.

-I shall sketch what I did with this supposition, in seven episodes · (1) I described this matter, giving an account of it that I tried-successfully, it seems to me-to make as openly plain and intelligible as anything except what I have just said about God and the soul. - As part of this search for clarity·, I explicitly stipulated that this matter had none of those 'forms' or 'qualities' that the scholastics argue about; allowed it to have only properties that our mind knows so naturally that no-one could even pretend not to. (2) I showed what the laws of nature were [= 'are'?], and arguing solely from the infinite perfections of God I tried to demonstrate all those laws that might have been called into question, and to show that they are such that even if God created many worlds there couldn't have been any in which these laws didn't hold. (3) I then showed how $\bullet$ these laws had the result that most of the matter of this chaos had to resolve itself 
into a certain orderly arrangement that made it resemble our heavens [here = 'sky']; and how at the same time ${ }^{-}$some of the parts of matter had to form an earth, some to form planets and comets, and yet other parts to form a sun and fixed stars. (4) And here I spread myself on the subject of light, explaining at some length -the nature of the light that had to be present in the sun and the stars, $\bullet$ how from there it travelled instantaneously across the immense distances of the heavens, and $\bullet$ how it bounced off the planets and comets towards the earth. (5) To this I added many points about the substance, position, movement and all the various qualities of these heavens and stars; and I thought I took this far enough to show that any features observed in the heavens and stars of our world would-or at least could-also be features of the -imaginary - world I was describing. (6) I went on from there to speak of the earth in particular: •how, although I had explicitly stipulated that God had put no gravity into the matter of which it was formed, all its parts nevertheless tended exactly towards its centre; •how, there being water and air on the earth's surface, the lay-out of the heavens and heavenly bodies and especially the moon had to cause an ebb and flow exactly like that of our tides, and also an east-to-west current of both water and air like the one we observe between the tropics; •how mountains, seas, springs and rivers could be formed naturally there, and $\bullet$ how metals could appear in mines, plants grow in fields, and generally •how all the bodies we call 'mixed' or 'composite' could come into being there. (7) Among other things, I worked hard to get out into the open and fully understood everything about the nature of fire, because as far I know it's the world's only source of light other than the stars. Thus I showed •how fire is formed, •how it is fuelled, •how sometimes it gives off heat but no light, and sometimes light without heat; •how it can produce different colours and other qualities in different bodies; •how it melts some bodies and hardens others; •how it can consume almost all bodies, or turn them into ashes and smoke; and finally $\bullet$ how it can through the sheer power of its action turn these ashes into glass. I took special pleasure in describing the formation of glass, because it seems to me as wonderful a transmutation as any in nature.

Still, I didn't mean to infer from all this that our world was created in the way I had been describing, for it is much more likely that from the beginning God made our world just as it had to be. But if we think of material things as developing gradually out of chaos, their nature is easier to grasp than if we considered them only in their ·present completed form. And there is nothing wrong with believing that God could have brought them about in that manner, starting with chaos, establishing the laws of nature, and then allowing nature to develop in a normal way in accordance with those laws. In particular, that belief doesn't malign the miracle of God's creation of the world. It is certain-and theologians generally agree - that God's activity in now preserving the world is just the same as his earlier activity of creating it, 'so the 'miracle of creation' is with us in full strength even now, whether or not the material world began in chaos.

[A long tradition, going back to Plato, held that plants are special in having 'vegetative souls', lower animals in also having 'sensitive souls', and humans in having 'rational souls' as well as the other two. In this paragraph, Descartes describes a thought-experiment concerning a possible living human body which he takes not to be equipped with a rational soul or any substitute for one; he tacitly rules out the other kinds of soul as well, but allows that something in this human body-namely, fire in the heart-might play the role that earlier thinkers assigned to the vegetative and sensitive souls.] Moving on from -inanimate bodies and $\bullet$ plants, I describe $\cdot$ animals and in particular -men. But I didn't yet know enough to speak of human bodies in the same way as I did of the other things-that is, 
by demonstrating effects from causes, and showing how and from what seeds nature must produce them. So I -settled for a second supposition, comparable with my supposition of a chaotic material world. Specifically, I- supposed that God formed the body of a man exactly like yours or mine both in outward shape and in the internal lay-out of its organs, making it out of nothing but the matter that I had described and not at first putting into it any rational soul or anything else to function as a vegetative or sensitive soul, except for his kindling in the human body's heart one of those fires without light that I had already explained, and whose nature I understood to be just the same as that of the fire that heats hay when it has been stored while wet.... And when I looked into what functions could occur in such a body I found precisely the ones that can occur in us without our thinking of them and hence without any co-operation from our soul-i.e. from that part of us, distinct from the body, whose nature is as I have pointed out simply to think. These functions are just the ones in which animals without reason may be said to resemble us. But I could find in my supposed living human body - none of the functions that we have only because we are men, the ones that depend on thought; though these all turned up later on, once I had supposed God to create a rational soul and join it to this body in a certain way that I described.

So that you can see how I went about doing this, I shall give my explanation of the movement of the heart and the arteries. [The next few pages-making nearly half of Part 5-are devoted to the circulation of the blood, and the function of the heart. They are of only historical interest, and are omitted here, except for three isolated fragments which help to convey the intellectual tone of the whole passage. [In the second of the three, the phrase 'mathematical demonstrations' means merely 'explanations conducted in terms of materialistic mechanism'.
Descartes isn't claiming to have done this work a priori; he is well aware that it is thoroughly empirical.]] - To readers who don't know any anatomy: before going on, please arrange to observe someone dissecting the heart of some large animal with lungs (for such a heart is in all respects enough like that of a man), and get him to show you its two chambers or cavities... • Those who don't know the force of mathematical demonstrations and aren't used to distinguishing true reasons from mere probabilities may be tempted to reject this explanation without examining it. To head them off, I would advise them that the movement I have just explained follows purely from

the layout of the organs of the heart, which can be seen with the naked eye, the heat in the heart, which can be felt with the fingers, and the nature of the blood, which can be discovered empirically;

and it follows just as necessarily from those three elements as does the movement of a clock from the force, position, and shape of its counterweights and wheels... • An English physician-William Harvey- - must be praised for having made the break-through on this subject. He is the first to teach that at the extremities of the arteries there are many small passages through which the blood they receive from the heart enters the small branches of the veins, from there going immediately back to the heart, so that its course is nothing but a perpetual circulation.

[Two technical terms in this paragraph: 'animal spirits' is the name for a supposed superfine fluid which acts as the body's hydraulic system. The 'common sense' was a supposed department of the mind in which inputs from different senses come together and are organized in relation to one another.] I had explained all these matters in enough detail in the treatise I had previously intended to publish. And then I had showed $\bullet$ how the nerves and muscles of the human body must be structured if the animal spirits inside them are to convey enough force to move its limbs....; • what 
changes must occur in the brain as causes of waking, sleep and dreams; •how light, sounds, smells, tastes, heat and the other qualities of external objects can imprint various ideas on the brain through the mediation of the senses; -how hunger, thirst, and the other internal passions can also send their ideas there. And I explained which part of the brain must be $\cdot$ identified with various supposed mental faculties-specifically, which part of the brain must be taken to be the 'common sense', where these ideas are received; the $\bullet$ memory, which preserves them; and the $\bullet$ imagination, which can change them in various ways, form them into new ideas, and, by distributing the animal spirits to the muscles, make the parts of this body move in as many different ways, and as appropriately to the objects of the senses and the internal passions, as the parts of our bodies can move without being guided by the will. You won't find that at all strange if $\bullet$ you know how many kinds of automata or moving machines the skill of man can construct with the use of very few parts, in comparison with the great multitude of bones, muscles, nerves, arteries, veins and all the other parts that are in the body of any animal, and if $\bullet$ this knowledge leads you to regard an animal body as a machine. Having been made by the hands of God, it is incomparably better organised-and capable of movements that are much more wonderful - than any that can be devised by man, but still it is just a machine.

I worked especially hard to show that if any such machines had the organs and outward shape of a monkey or of some other animal that doesn't have reason, we couldn't tell that they didn't possess entirely the same nature as these animals; whereas if any such machines bore a resemblance to our bodies and imitated as many of our actions as was practically possible, we would still have two very sure signs that they were nevertheless not real men. (1) The first is that they could never use words or other constructed signs, as we do to declare our thoughts to others. We can easily conceive of a machine so constructed that it utters words, and even utters words that correspond to bodily actions that will cause a change in its organs (touch it in one spot and it asks 'What do you mean?', touch it in another and it cries out 'That hurts!', and so on); but not that such a machine should produce different sequences of words so as to give an appropriately meaningful answer to whatever is said in its presence-which is something that the dullest of men can do. (2) Secondly, even though such machines might do some things as well as we do them, or perhaps even better, they would be bound to fail in others; and that would show us that they weren't acting through understanding but only from the disposition of their organs. For whereas reason is a universal instrument that can be used in all kinds of situations, these organs need some particular disposition for each particular action; hence it is practically impossible for a machine to have enough different $\bullet$ organs to make $\bullet$ it act in all the contingencies of life in the way our •reason makes -us act.

These two factors also tell us how men differ from beasts [= 'non-human animals']. For it's a remarkable fact no men (including even madmen) are so dull-witted or stupid that they can't arrange different words together so as to form an utterance that makes their thoughts understood; whereas no other animal, however perfect and well-endowed it may be, can do anything like that. It's not because they lack organs of speech; for we see that magpies and parrots can •utter words as we do yet can't • speak as we do-i.e. utter words while showing that they are thinking what they are saying. Whereas men who are born deaf and dumb, and thus at least as lacking in speech-organs as the beasts are, usually invent their own signs to make themselves understood by those 
whom they live with, who have the opportunity to learn their language. This doesn't show merely that the beasts have less reason than men; it shows that they don't have reason at all. Here is why. [This indented passage is faithful to Descartes's thought at this point, but it expands his words in a way that can't easily be indicated by $\cdot$ dots $\cdot$.]

Animals of a given species are unequal, as least to the extent that human beings are unequal; some of them, for instance, are much more easily trained than others. So we have the notion of beasts that are abler than or superior to their fellows. Now, obviously the ability to talk doesn't require much reason; so if any of the beasts had reason at all, we would expect the superior members of some species-high-grade monkeys or parrots, for example-to speak as well as the stupidest child, or at least as well as a child with a defective brain. But none of them do; which shows that their souls are completely different in nature from ours, and don't include any capacity to reason.

Don't confuse speech with the natural movements that are evidence of passions and can be imitated by machines as well as by animals. And don't think, as some of the ancients did, that the beasts speak a language that we don't understand! For if that were true, then since they have many organs that are analogous to ours, they could make themselves understood by us as well as by their fellows. It is another remarkable fact that although many animals show more skill than we do in some of their actions, yet the same animals show no skill at all in plenty of others; so what they do better doesn't prove that they have minds, for if it did, they would have better minds than any of us and would out-perform us in everything. It shows rather that they don't have minds at all, and that it is nature that acts in them according to the disposition of their organs. Similarly, we with all our skill can't count the hours and measure time as accurately as a clock consisting only of wheels and springs!

I went on to describe the rational soul, and showed that, unlike the other things of which I had spoken, it can't be derived from the powers of matter, but must be specially created as a sheer addition to the human body. The soul has been thought to be lodged in the human body like a helmsman in his ship, and this comparison may hold some of the way, specifically in the soul's ability to move the body's limbs; but I showed that the comparison doesn't tell the whole story, and that the soul must be more closely united with the body than the helmsman is with his ship·, because if it is to make up a real man it must have not only the power to move the body but also feelings and appetites like ours. I went on at some length about the soul, because it is one of the most important topics. Second only to the error of those who deny God-which I think I have adequately refuted above-there is no error that leads weak minds further from the straight path of virtue than that of imagining that the souls of the beasts are of the same nature as ours, and hence that after this present life we have nothing to fear or to hope for, any more than flies and ants do. When we know how different the beasts are from us, we are better placed to understand the arguments proving that our soul is of a nature entirely independent of the body, and thus not liable to die with it. And since we can't see any other causes that destroy the soul, we are naturally led to think that it is immortal. 


\section{Part 6}

It is now three years since I finished the treatise containing all these things. I was starting to revise it so as to put it in the hands of a publisher, when I learned that a scientific theory published a little while before by someone else had been condemned by people to whom I defer, giving them almost as much authority over my actions as my own reason has over my thoughts. [This refers to a work of Galileo's that was condemned by the Roman Catholic authorities in 1633.] I won't say that I accepted this theory, but only that until they censured it I hadn't noticed in it anything that I could imagine to be threatening either to religion or to the state, or, therefore, •anything that would have prevented me from putting it in writing if reason had convinced me of it. This made me fear that I might have gone wrong in one of my own theories, despite the care I had always taken never to adopt any new opinion that I couldn't conclusively demonstrate, and never to write anything that might work to anyone's disadvantage. That -fear. was enough to push me into changing my previous decision to publish my views. I had had very strong reasons for this previous decision, but my temperamental hatred of the business of writing books made it easy for me to find reasons for letting myself off. The reasons for and against are ones that I would like to state here, and perhaps you will be interested to know them. [The reasons for will occupy two paragraphs, ending on page 26.]

I have never claimed any great importance for the products of my own mind; and so long as the only fruits I gathered from the method I use were (1) solutions that I found satisfying for certain problems in the speculative sciences, and (2) my attempts to govern my own conduct by the principles I learned from my method, I didn't think I was obliged to write anything about it. For as regards (2) conduct: everyone is so full of his own wisdom that if changes in these matters could be made by people whom God hadn't set up as sovereigns over his people or to whom he has given enough grace and zeal to be prophets, we might find as many reformers as there are people! As regards (1): my speculations, much as I liked them I thought that other people had their own and perhaps liked them even more. But I acquired some general notions in physics and realized, as I began to test them in various special problems, how far-reaching they were and how different from the principles used up to now; and as soon as I saw that I thought I couldn't keep them to myself without offending gravely against the law that requires us to do all we can for the general welfare of mankind. For they-these scientific notions of mine-—showed me that we can get knowledge that would be very useful in life, and that in place of the speculative philosophy taught in the schools we might find a $\bullet$ practical philosophy through which

knowing the power and the actions of fire, water, air, the stars, the heavens and all the other bodies in our environment as clearly as we know the various crafts of our artisans, we could (like artisans) put these bodies to use in all the appropriate ways, and thus make ourselves the masters and (as it were) owners of nature.

This is desirable not only for the invention of innumerable devices that would give us trouble-free use of the fruits of the earth and all the goods we find there, but also, and most importantly, for the preservation of health, which is certainly the chief good and the basis for all the other goods in this life. For even the mind depends so much on the state of the 
bodily organs that if there is to be found a means of making men in general wiser and cleverer than they have been so far, I believe we should look for it in medicine. It is true that medicine as currently practised doesn't contain much of any significant use; but without wanting to put it down I'm sure that everyone, even its own practitioners, would admit -that all we know in medicine is almost nothing compared with what remains to be known, and - that we might free ourselves from countless diseases of body and of mind, and perhaps even from the infirmity of old age, if we knew enough about their causes and about all the remedies that nature has provided for us. Well then, having intended to spend my life in the pursuit of such indispensable knowledge, and having come upon a path that seemed to me to be bound to lead to it unless prevented by $\bullet$ the brevity of life or $\bullet$ the lack of experiments, I reached a conclusion about the best remedy against $\bullet$ these two difficulties. It was that I should give to the public a scrupulous account of everything I had discovered, little as it was; and should invite ${ }^{\bullet}$ the best minds to try to make further progress by helping with the necessary experiments, each according to his preference and his ability, and by communicating to the public everything $\bullet$ they learn. In this way, some could take over where others had left off; and thus, by combining the lives and labours of many people, we might get much further working together than anyone could do on his own.

[An expérience can be an experiment or a mere informal experience. This paragraph is mostly about experiments, but when Descartes refers to 'ones that just happen' he is clearly thinking of experiences, informal observations.] I also noticed something about experiments: the more we know, the more we need experiments. At the beginning, it is better to avail oneself only of •ones that just happen around us, ones that we can't be ignorant of unless we don't think at all; better, that is, than resorting to $\bullet$ more out-of-the-way and contrived experiments. Why? Because the more out-of-the-way events often mislead us when we don't yet know the causes of the more ordinary ones, and the factors they depend on are nearly always so special and so minute that it is very hard to spot them. But I went about things in the following order. $\bullet$ First I tried to discover in general the principles or first causes of everything that does or can exist in the world. For this I didn't look beyond God, who created the world; and I derived these principles only from certain seeds of truth that are naturally in our souls. -Next I examined the first and most ordinary effects deducible from these causes; and it seems to me that this procedure led me to the heavens, the stars, and an earth; and on the earth water, air, fire, minerals, and other such things that are the easiest to know because they are the most common and the simplest. •Then, when I wanted to move down to more particular things, I was confronted by such a variety that I didn't think the human mind could possibly sort out the forms or species of bodies that are on the earth from an infinity of others that could be there if God had chosen to put them there; from which I inferred that the only way of making these bodies useful to us was to reach the causes by way of the effects, and to make use of many special experiments. Later on, reviewing in my mind all the objects that have ever been present to my senses, I venture to say that I have never noticed anything in them that I couldn't quite easily explain by the principles I had discovered. But I must also admit that the power of nature is so ample and so vast, and these principles so simple and so general, that with almost any particular effect I know from the outset that it can be deduced from the principles in various different ways; my greatest difficulty usually being to $\bullet$ discover which of them actually applies. The only way I know to do ${ }^{\bullet}$ this is by returning to experiments, looking for ones whose outcomes 
would differ according to which explanation was the right one. I have now reached a point where I think I can see pretty well what line we should follow in devising most of the experiments that could help in this way; but I see also that I couldn't do them all myself, and couldn't afford to even if my income were a thousand times greater than it is, because there are so many of them and they are so difficult to do. And so $\cdot$ I have had to give up the idea of completing physical science all by myself $\cdot$; how far I get in the knowledge of nature will from now on depend on how many of these -crucial experiments. I am able to conduct. I was going to make this [meaning 'this whole situation'?] known in the book I had written, and to show there how generally beneficial such experiments could be, presenting this so openly and plainly that virtuous people would be obliged both to report to me the experimental results they had already achieved and to help me to work on the experiments that remained to be made. I mean really virtuous people-ones who desire the general good of mankind-not ones who merely claim to be virtuous or are merely thought to be so. [So much for the reasons for publishing; now for the reasons against. They end on page 29. In a moment or two we'll see Descartes speaking of 'this volume', referring to the book that was to include not just this Discourse but also three scientific essays: Optics, Meteorology, and Geometry.]

Since then, however, other thoughts have occurred to me that have made me change my mind, and think that my policy should be this:

I should go on writing down any of my discoveries that I consider to be at all important, doing do this as carefully as I would if I intended to have them published. - There are two reasons for this comprehensiveness and care. (1) It will give me all the more reason to examine them closely, as undoubtedly we always look more carefully at something we expect to be seen by others than at something we do only for ourselves (I have often found that something that seemed true when I first conceived it came to look false when I tried to write it down). (2) This plan will also ensure that I lose no opportunity to benefit the public if I can, and that if my writings have any value, those who get them after my death can use them as they see fit.

But I'm determined not to let them be published during my lifetime, so that I shan't lose any of the time I plan to devote to my self-instruction, being distracted either by opposition and controversy that my published works might arouse, or by whatever reputation they might gain for me. It's true that each of us is bound to do what he can to procure the good of others, and someone who doesn't help anyone else is strictly worthless; but it's also true that our concern -for others. should look beyond the present time, and that it is right to pass up chances to profit the living in order to do other things that will benefit later generations even more. -My present topic is an example of the latter theme.: I'm willing to tell you that the little I have learned so far is almost nothing compared with what I don't know but hope to be able to learn. -I expect my rate of success to accelerate becausegradually discovering truth in the sciences is like making money: a rich man has less trouble making large profits than he had making much smaller ones when he was poorer. Or the scientist may be compared with a military commander whose forces tend to grow in proportion to his victories, and who needs less skill to $\bullet$ take towns and provinces after -winning a battle than he needs just to $\bullet$ hold on after $\bullet$ losing one. For trying to overcome all the difficulties and errors that prevent our arriving at knowledge of the truth is a matter of fighting battles: when we accept some false opinion on an important question of general significance, that is a defeat, and we need much more skill to recover from it than we do to 
make good progress when we already have principles that are well-founded. Take my own case: if I have already discovered a few truths in the sciences (and I hope the contents of this volume will make you think I have found some), I can say that these discoveries are merely upshots of my having overcome five or six principal difficulties-and I see these as five or six battles in which luck was on my side. I even go so far as to say that I think I need to win only two or three more such battles in order to achieve my aims completely, and a at 41. I'm not too old to have remaining to me, in the normal course of nature, the time needed to do this. [He died at the age of 54.] But the more hopeful I am of being able to use my remaining years effectively, the more I think I am obliged to plan my time carefully; and I was certainly going to lose a lot of time if I published the basic principles of my physics. For although these principles are nearly all so evident that you need only understand them to believe them, and although I think I can demonstrate them all, there is no chance at all that they will square with the various opinions that others have, so that I foresee that -if I published them. I would often be distracted by the opposition they would arouse.

You may want to say:

That sort of opposition would be useful. Not only would it make you aware of your mistakes, but it would also enable others to have a better understanding of anything worthwhile that you may have discovered; and, as many heads are better than one, so these others might begin to use your results and to help you in turn with theirs.

Well, I recognize that I'm extremely prone to error, and I hardly ever trust the first thoughts that come to me; but I have seen how people can object to my scientific work., and that experience prevents me from expecting any benefit from that direction. For I have often already examined the judgments of •people whom I took to be my friends, of $\bullet$ others whom I thought to be neither friend nor foe, and of $\bullet$ others again whose malice and envy would, I knew, make them eager enough to reveal faults in my work. that my friends hadn't noticed because of their affection for me. But hardly ever has an objection been raised that I hadn't wholly foreseen, except for ones that were wildly irrelevant! Thus I have almost never encountered a critic of my views who didn't strike me as either less rigorous or less fair-minded than I am. Nor has it been my experience that previously unknown truths have been discovered through the disputations they carry on in the schools. For so long as each side is straining for victory, they try harder for plausibility than for good reasons; and being a good advocate for many years doesn't enable one to go on to be a better judge.

As for the benefit that others might get from learning about my thoughts, this couldn't amount to much because they're still not very developed: much more has to be done before they are ready for practical application. And I think I can say without vanity that if anyone is capable of making these further developments it must be myself rather than someone else-not that the world may not contain minds incomparably better than mine, but because no-one can conceive something as well when he learns it from someone else as when it's his own discovery. This is true in the present case-so true that I have often explained some of my opinions to highly intelligent persons who seemed to understand them really clearly at the time and then -found, when they repeated them back to me, that they almost always changed them in such a way that I could no longer acknowledge them as my own. I take this occasion to address a plea to future generations: Please don't ever believe that I am the source of an opinion you hear, unless I myself have made it public. I'm not in the least surprised 
by the absurdities attributed to all the ancient philosophers whose writings we don't possess, and what I conclude from these attributions is not - that their thoughts were highly unreasonable (they were some of the best minds of their time) but rather that their thoughts have been misreported. -I shall add some remarks about how the work of the ancients is used and viewed by later generations; you'll soon see how this bears on my present theme.

We see that it hardly ever happens that the followers of -an ancient philosopher surpass •him; and I'm sure that most of Aristotle's disciples of today would be happy to know as much about nature as he did, even if that meant never knowing anything that he didn't. They are like ivy, which doesn't tend to climb higher than the tree that supports it, and often even grows downward after reaching the treetop. It seems to me that philosophical disciples also 'grow downwards', or become somehow less knowledgeable than if they refrained from study, when, not content with knowing everything that is intelligibly explained in their author's writings, they want further to find there the solution to many problems about which he says nothing and about which perhaps he never thought. But this manner of philosophizing is very convenient for those with merely average minds, for the obscurity of the distinctions and principles they use enables them to speak about everything as confidently as if they knew what they are talking about, and to defend all they say against the subtlest and cleverest thinkers, and there's no convincing them that they are wrong. In this they seem to me like a blind man who lures his adversary into the depths of a very dark cellar so as to level the odds in their fight. These philosophers, I may say, have a reason for not wanting me to publish the philosophical principles that I use; for these are so very simple and evident that in publishing them I should, as it were, be opening windows and letting daylight into the cellar where the philosophers have gone down to fight. But even the best minds have no cause to want to know my views. For if they want to be able to speak about everything and acquire the reputation of being learned, they'll achieve this more readily by settling for plausibility, which is pretty easy to find in all kinds of subjects, than by seeking the $\bullet$ truth; for in some subjects the truth comes to light only gradually, while in others it forces us to own up to our ignorance. But if instead of vainly -seeming to know everything they prefer-as of course they should- knowing a few truths, and if they wish to follow a plan like mine, then I needn't tell them anything more than I have already said in this Discourse. For if they are capable of getting further than I have done, then of course they'll be capable of discovering for themselves everything I think I have discovered. Also, because I have examined everything in an orderly manner, what still remains for me to discover is bound to be intrinsically harder and more hidden than anything I have been able to discover up to now; and they-the philosophers I'm speaking of-—would have much less pleasure in learning it from me than in learning it for themselves. Besides, the practice they will get by first looking into easy matters and then gradually moving on to more difficult ones will be more useful to them than any instructions from me could be. For my part, I am convinced that if from my youth I had been •taught all the truths I have since tried to $\bullet$ demonstrate, and so had learned them easily, I might never have known any others; or at least I would never have acquired what I think I do have-a practised ability to find new truths whenever I set myself to look for them. In short, if there is any project that is best carried out by the person who began it, it is this one of mine.

True, one man can't possibly conduct all the experiments that may help in this work; but he can't usefully employ 
other hands than his own, except those of artisans or other such people, whom he could pay and who would be led by the hope of making money (a most effective motive!) to follow his instructions exactly. Voluntary helpers, who might offer to help him from curiosity or a desire to learn, usually promise more than they deliver, producing nothing but fine proposals that never come to anything. Also, any amount of time that they saved for him by their efforts would be exceeded by the time they would $\bullet$ take in collecting their expected reward-having certain difficulties explained to them, or at least receiving compliments and useless conversation. What about experiments that others have already made? Well, even if those others were willing to tell him about them (and those who call them 'secrets' never would)), the experiments in question are mostly made up of so many details or superfluous ingredients that it would be very hard for him to make out the truth in them. Besides, he would find most of these experiments were so badly explained-or indeed so wrong because the experimenters were straining to get results that appeared to conform with their principles-that if some of them were ppotentially - useful to him, the task of sorting those ones out would take more of his time than they were worth. Suppose this were the case:

There is someone in the world whom we know for sure to be capable of making discoveries of the greatest possible importance and public utility. Other men are accordingly eager to help him in every way to achieve his ends.

I don't see how they could do anything for him except - contribute towards the costs of the experiments he would need to conduct, and -prevent unwelcome visitors from wasting his free time. But I'm not casting myself in that role.: I am not so presumptuous as to want to promise anything extraordinary, nor do I feed on any vain idea that the public should take a great interest in my plans; and in any case I have too much self-respect to be willing to accept from anyone a favour that I might be thought not to deserve.

All these considerations taken together led me to decide three years ago that I didn't want to publish the treatise I had ready then, and even to resolve not to publish during my lifetime any other work that was as general in scope as that one, or any which would enable people to grasp the fundamentals of my physics. Since then, however, two further reasons have forced me to publish -along with this Discourse. some essays on particular topics-. Optics, Meteorology and Geometry- - and to give to the public some account of my actions and plans. (1) If I didn't, many people who knew of my earlier intention to have certain of my writings printed might suppose that my reasons for not doing so were more discreditable to me than they are. I'm not excessively fond of glory-I even venture to say that I dislike it, seeing it as opposed to the tranquillity that I value above everything else-but I have never tried to hide my actions as though they were crimes, or gone to a lot of trouble to remain unknown. If I had done this, I thought, I would have been doing myself an injustice; and moreover that $\bullet$ trouble would have created a kind of disturbance which would-like fame-—have been opposed to the perfect peace of mind I am seeking. And since my indifference about whether I was well-known or not made it unavoidable that I should gain some sort of reputation, I thought I should do my best at least to avoid getting a bad one. (2) Every day increases my awareness of how my project of self-instruction is being held back by the need for innumerable experiments that I need and can't possibly conduct without the help of others. Although I don't flatter myself with any expectation that the public will share my interests, still I'm unwilling to let myself down by giving those who come after me cause to reproach me some day 
on the grounds that I could have left them many far better things if I hadn't neglected to show them how they could contribute to my projects.

I thought it convenient for me to choose certain subjects which, without being highly controversial or revealing more of my principles than I wanted to, would still reveal well enough my scientific ability or lack of it. I can't tell if I have succeeded in this, and I don't want to get in ahead of anyone else's judgments on my writings by speaking about them myself. But I shall be very glad if they are examined; and so that people should feel invited to do this, I beg all who have any objections to send them to my publisher; when he informs me about them I'll try to bring it about that my replies are appended to them 'when they are published. so that readers can see both sides together, and be better judges of which is true. I don't promise to make very long replies, but only to admit my errors very frankly if I recognize them; and where I can't see that I have gone wrong I shall simply say what I consider is required for defending what I have written. I shan't introduce any new material, so as not to get endlessly caught up in one topic after another.

If you are startled at first by some of the statements I make at the beginning of the Optics and Meteorology, because I call them 'suppositions' and seem not to be interested in proving them, please have the patience to read the whole book attentively, and I trust you will be satisfied. For it seems to me that reasons are interlaced in such a way that just as the last are proved by the first, which are their causes, so the first are proved by the last, which are their effects. Don't think that I am here committing the fallacy that logicians call 'arguing in a circle'; for experience makes most of these effects quite certain, so that the causes from which I deduce them serve not so much to $\bullet$ prove them as to $\bullet$ explain them-indeed, on the contrary, it is the effects that prove the causes. I used the term 'suppositions' simply to indicate that although I think I can deduce them from the primary truths expounded above, I have particularly wanted not to do so. Why? Because I wanted to prevent certain people from taking the opportunity to construct, on what they believe to be my principles, some extravagant philosophy for which I would be blamed. (I'm talking about the kind of person who imagines that when someone else has pondered something for twenty years and sketched it to him in two or three words, he can learn it in a single day; the kind of person who, the more penetrating and lively his mind is, the more prone to error he is and the less capable of truth!) As for the views that are entirely mine, I don't apologize for their novelty, especially because careful attention to the reasons for them will show them to be simple and in agreement with common sense-so much so that they will seem less extraordinary and strange than any other views that might be taken on the same subjects. I don't boast of being the first to discover any of them, but I do claim this: When I accept something, it is because reason has convinced me of it, not because it has already been said by someone else or because it hasn't!

If workmen can't manage, straight off, to put into operation the invention -for cutting lenses explained in the Optics, I don't think that that shows it to be defective. For much skill and practice are needed for making and adjusting the machines I have described; and although my description provides all the details, it would be astonishing if someone succeeded at the first attempt.... I'm writing in French, my native language, rather than in Latin, the language of my teachers, because I hope for a better judgment of my opinions from $\bullet$ those who use only their natural reason in all its purity than I would get from those who only trust old books. As for those who combine -good sense with •learning-the only judges I wish to have-I'm sure they won't be so partial 
to Latin as to refuse to listen to my arguments because I expound them in the vernacular.

For the rest, I don't want to speak here in detail about the further progress I hope to make in the sciences, or to make any public promise that I am not sure of keeping. I will say only that I have resolved to devote my remaining years purely to trying to acquire knowledge of nature from which we can be derived rules in medicine that are more reliable than those we have had up till now. I'm temperamentally strongly opposed to any other projects, especially to any that can help some people only by harming others; so that if circumstances forced me to engage in one like that, I don't think I could succeed in it. Of this I make here a public declaration, fully recognizing that it can't serve to make me eminent in the world-but then I don't in the least want to be. And I shall always hold myself more obliged to those whose favour enables me to enjoy uninterrupted leisure than to any who might offer me the most honourable employments in the world. 